\title{
Effect of a diet program and aerobic exercise in class II and class III obese children with chronic kidney disease
}

\author{
DOI: https://doi.org/10.5114/pq.2020.100292
}

\author{
Alaa R. Morgan ${ }^{1,2}$, Faten E. Ali, ${ }^{3,4}$, Magda G. Sedhom ${ }^{5}$ \\ ${ }^{1}$ Department of Physical Therapy for Growth and Development Disorders in Children and Its Surgery, Faculty of Physical \\ Therapy, Cairo University, Cairo, Egypt \\ ${ }^{2}$ El-Kasr Al Ainy Hospital, Cairo University, Cairo, Egypt \\ ${ }^{3}$ Department of Physical Therapy for Cardiovascular Disorders and Geriatrics, Faculty of Physical Therapy, \\ Cairo University, Cairo, Egypt \\ ${ }^{4}$ Faculty of Physical Therapy, Delta University for Science and Technology, Cairo, Egypt \\ ${ }^{5}$ Basic Science Department, Faculty of Physical Therapy, Cairo University, Cairo, Egypt
}

\section{Abstract}

Introduction. Obesity is a significant factor in the development of numerous chronic kidney diseases. Chronic kidney disease reduces exercise capacity and muscle strength, which is suggested to improve through exercise. The study investigated the effect of a diet program and aerobic exercises in obese children with chronic kidney disease.

Methods. Thirty children of both sexes aged 12-16 years with class II or class III obesity in accordance with body mass index (BMI) and first 2 stages of chronic kidney disease were selected from Paediatric Nephrology Unit, Cairo University. They were randomly assigned into 2 equal groups. The control group received routine medical treatment (blood pressure control, treatment of hyperlipidaemia, non-steroidal anti-inflammatory drugs). The experimental group received routine medical treatment in addition to a diet program and aerobic exercises 3 times per week for 3 months. Blood urea nitrogen, serum creatinine, C-reactive protein, urine albumin, sodium, potassium, cholesterol, high-density lipoprotein, low-density lipoprotein, and triglycerides were evaluated before and after treatment in both groups.

Results. There were significant differences between the mean pre- and post-treatment parameters of kidney function, lipid profile, and BMI within each group $(p<0.05)$. Significant differences were observed in the mean parameters of kidney function, lipid profile, and BMI between the 2 groups after treatment in favour of the experimental group $(p<0.05)$.

Conclusions. As the experimental group showed more positive results, the diet control program and aerobic exercise had a positive effect in class II and class III obese children with chronic kidney disease.

Key words: diet program, aerobic exercise, obesity, chronic kidney disease

\section{Introduction}

Chronic kidney disease (CKD) affects approximately $7-12.5 \%$ of the population in the United States of America. It is considered a predisposing risk factor for cardiovascular disease, one of the primary causes of morbidity and mortality in children with CKD. Cardiovascular hazard occurs early in CKD patients $[1,2]$. Dyslipidaemia in CKD, typically manifested by increased triglyceride level and reduced high-density lipoprotein (HDL), is associated with a high risk for atherosclerosis [3].

Low exercise capacity in children with CKD is due to various factors, such as anaemia, sedentary lifestyle, chronic inflammation, and cardiovascular dysfunction, to enumerate the main reasons [4, 5]. Many evidence-based reports suggest that children with renal diseases are at a high risk of low exercise capacity and decreased muscle strength, which can have an unfavourable impact on their lives $[4,6]$.

Childhood obesity can pathologically affect many body organs and lead to serious problems, which include hypertension, dyslipidaemia, insulin resistance, dysglycaemia, fatty liver disease, and psychosocial complications. In general, comorbidities of children obesity may be categorized under physical and psychosocial issues [7-9].
Renal disease treatments include nutritional restriction to lower protein consumption and to adjust electrolyte imbalance. It is important to pay attention to lipid intake, so fat utilization should be regulated in quantity and quality in a diet program [10]. Exercise training is essential and has many benefits for all children with renal diseases. Exercise is divided into controlled outpatient programs in a rehabilitation centre and home exercise programs $[5,7,11]$.

Although there is strong evidence in adults that exercise is beneficial, it would be wrong to assume that this is also the case in children, who have additional complications, e.g., impaired growth and development. Thus, this study was carried out to analyse the effect of a diet control program and aerobic exercise in class II and class III obese children with CKD after successive 3 months of treatment.

\section{Subjects and methods}

Study design

The study followed a pretest-posttest experimental design. The independent variable was obese children with CKD. The measured variables were kidney function (blood urea nitrogen, serum creatinine, C-reactive protein, urine albumin, 
sodium, and potassium), lipid profile (cholesterol, HDL, lowdensity lipoprotein [LDL], triglycerides), and body mass index (BMI), evaluated before and after 3 months of treatment.

\section{Sample size determination}

The G*Power 3.1 software (Heinrich Heine University, Düsseldorf, Germany) was used to calculate the sample size with $90 \%$ power, 0.05 type I error (2-tailed), and effect size of 0.99 . As a result, 15 subjects were recruited in each group and the total number of participants was 30 .

The inclusion criteria were as follows: children of both sexes, age 12-16 years, class II or class III obesity in accordance with BMI classification (35-40 kg/m²), and first 2 stages of CKD. Patients were excluded if they had genetic obesity syndromes, had undergone a surgical procedure within the previous 3 months, had congenital or acquired skeletal deformities or any neurological deficits, such as convulsions or involuntary movements, or were receiving muscle relaxants. Also, children with renal, bone marrow, or stem cell transplantation, or leukaemia or HIV in the previous 5 months, as well as those with a history of a structural heart disease were excluded [12].

\section{Randomization method}

The patients were randomly divided into 2 groups: in the first group (control group, 15 children), the odd numbers were selected, while in the second group (experimental group, 15 children), the even numbers were selected.

\section{Instrumentation}

A valid and reliable height and weight measuring scale system was used for detecting the weight and height of the children and calculating BMI.

A fully automated machine processed the blood samples for laboratory investigations of blood urea nitrogen, serum creatinine, C-reactive protein, urine albumin, sodium, potassium, and lipid profile.

\section{Assessment procedures}

Each child underwent the same evaluation, which was performed by the same therapist at the beginning and after 3 months of the treatment. The evaluation procedures included the measurement of blood urea nitrogen, serum creatinine, C-reactive protein, urine albumin, sodium, potassium, cholesterol, HDL, LDL, triglycerides, and BMI before and after 3 months of treatment.

\section{Treatment procedures}

The control group received routine medical treatment as prescribed by the physician, including aggressive blood pressure control, treatment of hyperlipidaemia, radiocontrast media to avoid nephrotoxins, and non-steroidal anti-inflammatory drugs. The experimental group received routine medical treatment in addition to a diet program (low-calorie diet) and aerobic exercise. A 10-minute warm-up and stretching were performed, then aerobic exercise was carried out on a cycle ergometer for 20 minutes at $15 \mathrm{~W}$, followed by walking on a treadmill for 10 minutes and 10-minute cool-down/ relaxation exercises, 3 times per week for 3 months.

\section{Data analysis and statistical design}

The Statistical Package for the Social Sciences (version 20 for Windows; SPSS Inc., Chicago, USA) was used for data analysis. Data were expressed as mean \pm standard deviation. A comparison between the mean values of age, height, and $\mathrm{BMI}$ in the 2 groups measured before treatment was performed with unpaired $t$-test. MANOVA served to compare within- and between-group effects. Values of $p \leq 0.05$ were considered significant.

\section{Ethical approval}

The research related to human use has complied with all the relevant national regulations and institutional policies, has followed the tenets of the Declaration of Helsinki, and has been approved by the Ethical Scientific Committee of the Faculty of Physical Therapy, Cairo University (approval No.: P.T.REC/012/001861). The Pan African Clinical Trials Registry number is PACTR201804003311164.

\section{Informed consent}

Informed consent has been obtained from the parents of all individuals included in this study.

\section{Results}

None of the patients in either treatment group dropped out throughout the study period. The mean age of the children in the control and the experimental groups was $14.20 \pm$ 1.196 and $14.10 \pm 1.25$ years, respectively. The mean height of the control and experimental groups participants was $153.6 \pm 6.7$ and $152.7 \pm 6.8 \mathrm{~cm}$, respectively. The mean BMI of the children in the control and the experimental groups equalled $34.9 \pm 7.8$ and $36.6 \pm 2.8 \mathrm{~kg} / \mathrm{m}^{2}$, respectively. There was no significant difference in the mean values of age, height, or BMI between the groups $(p>0.05)$, as shown in Table 1.

Table 1. General characteristics (mean $\pm S D$ ) of subjects in both groups

\begin{tabular}{|l|c|c|c|}
\hline Item & Age (years) & Height $(\mathrm{cm})$ & BMI $\left(\mathrm{kg} / \mathrm{m}^{2}\right)$ \\
\hline Control group & $14.20 \pm 1.196$ & $153.6 \pm 6.7$ & $34.9 \pm 7.8$ \\
\hline Experimental group & $14.10 \pm 1.25$ & $152.7 \pm 6.8$ & $36.6 \pm 2.8$ \\
\hline$t$ & 0.258 & 0.419 & -0.915 \\
\hline$p$ & 0.798 & 0.677 & 0.366 \\
\hline Significance & NS & NS & NS \\
\hline
\end{tabular}

$\mathrm{BMI}$ - body mass index, NS - not significant

\section{The effect of treatment on kidney function}

Table 2 presents the differences between the control and the experimental groups in the pre- and post-treatment mean values of blood urea nitrogen, serum creatinine, C-reactive protein, urine albumin, sodium, and potassium. Statistically non-significant differences $(p>0.05)$ were observed between the groups before treatment. There were highly statistically significant differences $(p<0.05)$ after treatment in favour of the experimental group. Also, significant differences between pre- and post-treatment values were indicated within each group $(p<0.05)$. 
Table 2. Mean values of blood urea nitrogen, serum creatinine, C-reactive protein, urine albumin, sodium, and potassium

\begin{tabular}{|c|c|c|c|c|}
\hline Item & $\begin{array}{l}\text { Before treatment } \\
\quad(\text { mean } \pm S D)\end{array}$ & $\begin{array}{l}\text { After treatment } \\
(\text { mean } \pm S D)\end{array}$ & $p$ & Significance \\
\hline $\begin{array}{l}\text { Blood urea nitrogen } \\
\text { Control group } \\
\text { Experimental group } \\
\text { Significance }\end{array}$ & $\begin{array}{c}20.45 \pm 5.33 \\
19.25 \pm 6 \\
p=0.536 \\
\text { NS }\end{array}$ & $\begin{array}{c}16.45 \pm 4 \\
10 \pm 2.2 \\
p=0.001 \\
S\end{array}$ & $\begin{array}{l}0.002 \\
0.001\end{array}$ & $\begin{array}{l}S \\
S\end{array}$ \\
\hline $\begin{array}{l}\text { Serum creatinine } \\
\text { Control group } \\
\text { Experimental group } \\
\text { Significance }\end{array}$ & $\begin{array}{c}1.64 \pm 0.24 \\
1.7 \pm 0.25 \\
p=0.169 \\
\text { NS }\end{array}$ & $\begin{array}{c}1.3 \pm 0.22 \\
0.79 \pm 0.14 \\
p=0.001 \\
S\end{array}$ & $\begin{array}{l}0.004 \\
0.001\end{array}$ & $\begin{array}{l}S \\
S\end{array}$ \\
\hline $\begin{array}{l}\text { C-reactive protein } \\
\text { Control group } \\
\text { Experimental group } \\
\text { Significance }\end{array}$ & $\begin{array}{c}14.1 \pm 5.44 \\
14.5 \pm 3.7 \\
p=0.825 \\
\text { NS }\end{array}$ & $\begin{array}{c}11.3 \pm 3.8 \\
5.5 \pm 2.3 \\
p=0.001 \\
S\end{array}$ & $\begin{array}{l}0.003 \\
0.001\end{array}$ & $\begin{array}{l}S \\
S\end{array}$ \\
\hline $\begin{array}{l}\text { Urine albumin } \\
\text { Control group } \\
\text { Experimental group } \\
\text { Significance }\end{array}$ & $\begin{array}{c}74.9 \pm 23 \\
69.65 \pm 20 \\
p=0.753 \\
\text { NS }\end{array}$ & $\begin{array}{c}52.1 \pm 22 \\
24.2 \pm 9.2 \\
p=0.001 \\
S\end{array}$ & $\begin{array}{l}0.002 \\
0.001\end{array}$ & $\begin{array}{l}S \\
S\end{array}$ \\
\hline $\begin{array}{l}\text { Sodium } \\
\text { Control group } \\
\text { Experimental group } \\
\text { Significance }\end{array}$ & $\begin{array}{c}174.6 \pm 27.3 \\
180.35 \pm 29 \\
p=0.471 \\
\text { NS }\end{array}$ & $\begin{array}{c}152.7 \pm 16.1 \\
131.4 \pm 8.2 \\
p=0.002 \\
S\end{array}$ & $\begin{array}{l}0.003 \\
0.001\end{array}$ & $\begin{array}{l}S \\
S\end{array}$ \\
\hline $\begin{array}{l}\text { Potassium } \\
\text { Control group } \\
\text { Experimental group } \\
\text { Significance }\end{array}$ & $\begin{array}{c}9.55 \pm 2.7 \\
10.88 \pm 3 \\
p=0.076 \\
\text { NS }\end{array}$ & $\begin{array}{c}6.82 \pm 1.5 \\
4.08 \pm 0.68 \\
p=0.001 \\
S\end{array}$ & $\begin{array}{l}0.002 \\
0.001\end{array}$ & $\begin{array}{l}S \\
S\end{array}$ \\
\hline
\end{tabular}

NS - not significant, S - significant

Table 3. Mean values of lipid profile parameters and BMI

\begin{tabular}{|c|c|c|c|c|}
\hline Item & $\begin{array}{l}\text { Before treatment } \\
\quad(\text { mean } \pm S D)\end{array}$ & $\begin{array}{l}\text { After treatment } \\
(\text { mean } \pm S D)\end{array}$ & $p$ & Significance \\
\hline $\begin{array}{l}\text { Cholesterol } \\
\text { Control group } \\
\text { Experimental group } \\
\text { Significance }\end{array}$ & $\begin{array}{c}209.46 \pm 24.8 \\
199.86 \pm 25.7 \\
p=0.815 \\
\text { NS }\end{array}$ & $\begin{array}{c}191.86 \pm 19.8 \\
149.53 \pm 14.9 \\
p=0.001 \\
S\end{array}$ & $\begin{array}{l}0.005 \\
0.001\end{array}$ & $\begin{array}{l}S \\
S\end{array}$ \\
\hline $\begin{array}{l}\text { LDL } \\
\text { Control group } \\
\text { Experimental group } \\
\text { Significance }\end{array}$ & $\begin{array}{c}134 \pm 16 \\
139.65 \pm 17.4 \\
p=0.094 \\
\text { NS }\end{array}$ & $\begin{array}{c}120.8 \pm 12.9 \\
91.73 \pm 9.3 \\
p=0.001 \\
S\end{array}$ & $\begin{array}{l}0.003 \\
0.001\end{array}$ & $\begin{array}{l}S \\
S\end{array}$ \\
\hline $\begin{array}{l}\text { HDL } \\
\text { Control group } \\
\text { Experimental group } \\
\text { Significance }\end{array}$ & $\begin{array}{c}37.6 \pm 5.4 \\
37.2 \pm 5.2 \\
p=0.777 \\
\text { NS }\end{array}$ & $\begin{array}{l}43.2 \pm 4.3 \\
50.2 \pm 3.2 \\
p=0.001 \\
S\end{array}$ & $\begin{array}{l}0.002 \\
0.001\end{array}$ & $\begin{array}{l}S \\
S\end{array}$ \\
\hline $\begin{array}{l}\text { Triglycerides } \\
\text { Control group } \\
\text { Experimental group } \\
\text { Significance }\end{array}$ & $\begin{array}{c}202.2 \pm 24.7 \\
192.5 \pm 21.2 \\
p=0.074 \\
\text { NS }\end{array}$ & $\begin{array}{c}181.2 \pm 18 \\
129.7 \pm 10.3 \\
p=0.001 \\
S\end{array}$ & $\begin{array}{l}0.003 \\
0.001\end{array}$ & $\begin{array}{l}S \\
S\end{array}$ \\
\hline $\begin{array}{l}\text { BMI } \\
\text { Control group } \\
\text { Experimental group } \\
\text { Significance }\end{array}$ & $\begin{array}{c}36.8 \pm 2.78 \\
37.28 \pm 3.7 \\
p=0.510 \\
\text { NS }\end{array}$ & $\begin{array}{c}30.9 \pm 3 \\
23.9 \pm 2.6 \\
p=0.006 \\
S\end{array}$ & $\begin{array}{l}0.004 \\
0.001\end{array}$ & $\begin{array}{l}S \\
S\end{array}$ \\
\hline
\end{tabular}

LDL - low-density lipoprotein, HDL - high-density lipoprotein, BMI - body mass index, NS - not significant, S - significant 
The effect of treatment on lipid profile and BMI

Table 3 depicts the differences between the control and the experimental groups in the pre- and post-treatment mean values of lipid profile parameters (cholesterol, LDL, HDL, and triglycerides) and BMI. Statistically non-significant differences $(p>0.05)$ were observed between the groups before treatment. There were highly statistically significant differences $(p<0.01)$ after treatment in favour of the experimental group. Also, significant differences between pre- and posttreatment values were indicated within each group $(p<0.05)$.

\section{Discussion}

Children with CKD obtain decreased results on exercise tolerance tests, such as the peak oxygen uptake test, or on functional capacity tests and the gradually progressive aerobic cardiovascular endurance run test [4]. So, this study was conducted to investigate the effect of a diet program and aerobic exercises on kidney function, lipid profile, and $\mathrm{BMI}$ in class II and III obese children with CKD.

The results of the current study revealed significant differences between pre- and post-treatment mean values of blood urea nitrogen, serum creatinine, C-reactive protein, urine albumin, sodium, potassium, lipid profile parameters, and BMI within each group. Also, there were significant differences between the groups after treatment in favour of the experimental group.

The improvement at the end of the treatment program in the control group can be due to the use of medical treatment, which had an enhancing effect on all the measured variables. These results agree with those achieved in a study that investigated the effect of 12-month treatment with atorvastatin on proteinuria and renal disease progress among 56 CKD children. After 12 months, protein voiding in urine and the progress of renal disease were improved in patients treated with atorvastatin [13].

The improvement in the experimental group observed at the end of the treatment program can be attributed to the low-fat, low-carbohydrate Mediterranean diet, which exerts a favourable effect on CKD children with or without diabetes mellitus, with regard to urinary albumin voiding and glomerular filtration rate [14].

Also, the more effective results in the experimental group may be due to reducing weight as a result of diet and exercises. Wilson et al. [15] reported that physical exercises interference was an additional tool in children and adolescent obesity management. Diet-only and diet with exercise treatment reduces weight and improves metabolic profile and cardiovascular indices. Also, the mentioned study revealed that adding exercise to dietary interference resulted in a considerable adjustment of HDL cholesterol, fasting glucose, and fasting insulin levels.

The results of this study are in line with those obtained by Rahmy et al. [16], who performed research among 50 patients with stages 3 and 4 of CKD, divided into 2 groups. The study group received moderate aerobic exercises and the control group received their medications only. Urine and blood samples were collected for determining glomerular filtration rate, serum urea, serum creatinine, and serum lipid profile before the initiation of the training program and after the completion of the study. The researchers concluded that moderate aerobic exercises improved kidney function and lipid profile and could delay progression of CKD stages 3 and 4.

One of the mechanisms that clarify the effective consequences of exercise is fat usage via lipid oxidation through exercise. Training and caloric reduction constitute an effective method for treatment of obesity which helps reduce weight, decrease infection, and achieve a long-term goal of improving life quality $[17,18]$. The results of this study also agree with the outcomes obtained by Aucella et al. [19], who indicate that systematic exercises can support psychological and functional enhancement and ultimately increase the quality of life in CKD patients.

Most of the previous studies on CKD in adults found a positive effect of exercises on kidney function, quality of life, and BMI. Regular exercise (regardless of type, intensity, length of intervention, or supervision) showed a statistically significant decrease in blood HDL level. An improvement in serum creatinine, albumin, and general protein was observed at the end of treatment. Research among adults and children revealed a strong correlation between good results of serum creatinine and albumin levels. In turn, no study defined adverse effects of exercises in CKD adults [20].

This may be attributed to the end result of energy control for renal function and CKD progress. In one trial, 24-hour proteinuria was decreased by incorporation of a diet and exercise regimen. Two additional trials with a dietary intervention showed a remarkable reduction of proteinuria [21].

Aerobic exercises, as well as a dietary program markedly decrease BMI. Interestingly, resistance exercise may lower trunk fat mass without reducing BMI, which suggests magnification in lean body mass. Data on the result of energy management on the nature of life imply a useful effect [22].

\section{Limitations}

There was a difficulty in persuading parents to engage their children in the exercise group (experimental group).

\section{Conclusions}

A diet control program and aerobic exercise in addition to medical intervention have a favourable effect on kidney function, lipid profile, and BMI in class II and III obese children with CKD.

\section{Acknowledgements}

We are greatly thankful to everyone who participated in this study.

\section{Disclosure statement}

No author has any financial interest or received any financial benefit from this research.

\section{Conflict of interest}

The authors state no conflict of interest.

\section{References}

1. Trifirò G, Sultana J, Giorgianni F, Ingrasciotta Y, Buemi M, Muscianisi $\mathrm{M}$, et al. Chronic kidney disease requiring healthcare services: a new approach to evaluate epidemiology of renal disease. Biomed Res Int. 2014;2014: 268362; doi: 10.1155/2014/268362.

2. Sarnak MJ, Levey AS, Schoolwerth AC, Coresh J, Culleton B, Hamm LL, et al. Kidney disease as a risk factor for development of cardiovascular disease: a statement from the American Heart Association Councils on Kidney in Cardiovascular Disease, High Blood Pressure Research, Clinical Cardiology, and Epidemiology and Prevention. Hypertension. 2003;42(5):1050-1065; doi: 10.1161/01.HYP.0000102971.85504.7c. 
3. Visconti L, Benvenga S, Lacquaniti A, Cernaro V, Bruzzese A, Conti G, et al. Lipid disorders in patients with renal failure: role in cardiovascular events and progression of chronic kidney disease. J Clin Transl Endocrinol. 2016;6:8-14; doi: 10.1016/j.jcte.2016.08.002.

4. Schaar B, Feldkötter M, Nonn JM, Hoppe B. Cardiorespiratory capacity in children and adolescents on maintenance haemodialysis. Nephrol Dial Transplant. 2011; 26(11):3701-3708; doi: 10.1093/ndt/gfr014.

5. Clapp EL, Bevington A, Smith AC. Exercise for children with chronic kidney disease and end-stage renal disease. Pediatr Nephrol. 2012;27(2):165-172; doi: 10.1007/ s00467-010-1753-1.

6. Weaver DJ Jr, Kimball TR, Knilans T, Mays W, Knecht SK, Gerdes YM, et al. Decreased maximal aerobic capacity in pediatric chronic kidney disease. J Am Soc Nephrol. 2008;19(3):624-630; doi: 10.1681/ASN.2007070773.

7. Konstantinidou E, Koukouvou G, Kouidi E, Deligiannis A, Tourkantonis A. Exercise training in patients with endstage renal disease on hemodialysis: comparison of three rehabilitation programs. J Rehabil Med. 2002;34(1):4045; doi: 10.1080/165019702317242695.

8. Han JC, Lawlor DA, Kimm SYS. Childhood obesity 2010: progress and challenges. Lancet. 2010;375(9727): 1737-1748; doi: 10.1016/S0140-6736(10)60171-7.

9. Güngör NK. Overweight and obesity in children and adolescents. J Clin Res Pediatr Endocrinol. 2014;6(3):129143; doi: 10.4274/Jcrpe.1471.

10. Endo A. A historical perspective on the discovery of statins. Proc Jpn Acad Ser B Phys Biol Sci. 2010;86(5): 484-493; doi: 10.2183/pjab.86.484.

11. Lustig RH, Weiss R. Disorders of energy balance. In: Sperling MA (ed.), Pediatric endocrinology, $3^{\text {rd }}$ ed. Philadelphia: Saunders; 2008; 788-838.

12. Clark SL, Denburg MR, Furth SL. Physical activity and screen time in adolescents in the chronic kidney disease in children (DKiD) cohort. Pediatr Nephrol. 2016;31(5): 801-808; doi: 10.1007/s00467-015-3287-z.

13. Bianchi S, Bigazzi R, Caiazza A, Campese VM. A controlled, prospective study of the effects of atorvastatin on proteinuria and progression of kidney disease. Am J Kidney Dis. 2003;41(3):565-570; doi: 10.1053/ajkd.2003. 50140.

14. Lacquaniti A, Bolignano D, Campo S, Perrone C, Donato V, Fazio MR, et al. Malnutrition in the elderly patient on dialysis. Ren Fail. 2009;31(3):239-245; doi: 10.1080/ 08860220802669891.

15. Wilson PW, D'Agostino RB, Levy D, Belanger AM, Silbershatz $\mathrm{H}$, Kannel WB. Prediction of coronary heart disease using risk factor categories. Circulation. 1998;97(18): 1837-1847; doi: 10.1161/01.cir.97.18.1837.

16. Rahmy AF, Afifi WM, Ghorab AAM, Mostafa HA. Effect of moderate aerobic exercises on kidney function and lipid profile in chronic kidney disease patients. J Egypt Soc Nephrol Transplant. 2016;16(3):97-105.

17. Tirosh A, Golan R, Harman-Boehm I, Henkin Y, Schwarzfuchs D, Rudich A, et al. Renal function following three distinct weight loss dietary strategies during 2 years of a randomized controlled trial. Diabetes Care. 2013;36(8): 2225-2232; doi: 10.2337/dc12-1846.

18. Ho M, Garnett SP, Baur LA, Burrows T, Stewart L, Ne ve $M$, et al. Impact of dietary and exercise interventions on weight change and metabolic outcomes in obese children and adolescents: a systematic review and metaanalysis of randomized trials. JAMA Pediatr. 2013;167(8): 759-768; doi: 10.1001/jamapediatrics.2013.1453.
19. Aucella F, Battaglia Y, Bellizzi V, Bolignano D, Capitanini A, Cupisti A. Physical exercise programs in CKD: lights, shades and perspectives: a position paper of the "Physical Exercise in CKD Study Group" of the Italian Society of Nephrology. J Nephrol. 2015;28(2):143-150; doi: 10.1007/s40620-014-0169-6.

20. Heiwe S, Jacobson SH. Exercise training for adults with chronic kidney disease. Cochrane Database Syst Rev. 2011;10:CD003236; doi: 10.1002/14651858.CD003236. pub2.

21. Giannaki CD, Stefanidis I, Karatzaferi C, Liakos N, Roka V, Ntente I, et al. The effect of prolonged intradialytic exercise in hemodialysis efficiency indices. ASAIO J. 2011;57(3):213-218; doi: 10.1097/MAT.0b013e31821 5 dc9e.

22. Paglialonga F, Lopopolo A, Scarfia RV, Galli MA, Consolo S, Brivio A, et al. Correlates of exercise capacity in pediatric patients on chronic hemodialysis. J Ren Nutr. 2013;23(5):380-386; doi: 10.1053/j.jrn.2013.04.006. 